Con motivo de la reciente exposición en el Hospital Real de Granada, el cuadro ha sido restaurado, lo que ha permitido apreciar en su factura, como se señala en la ficha del catálogo, una técnica ticianesca que Alonso Cano habría conseguido del estudio de las colecciones reales de pintura a las que tuvo acceso junto a Velázquez tras el incendio sufrido en el palacio del Buen Retiro en 1640. La identificación que allí se hace del edificio representado en la pintura con el antiguo palacio de los Guzmanes en Loeches se utiliza para atribuir el encargo de la pintura al conde-duque de Olivares quien la habría donado a la Real Congregación del Santo Cristo de San Ginés. De acuerdo con esta apreciación se propone en la citada ficha «(...) retrasaría la fecha de ejecución de la obra hasta 1640 ó, más probablemente, 1643, cuando el valido reside en Loeches tras caer en desgracia» ${ }^{29}$.

Conforme a los documentos que han sido revisados para la realización de esta investigación, sabemos que en 1679 - fecha en que se realiza el testamento cerrado de don Pablo Antonio Suárez- el lienzo estaba en la colección de doña Francisca Ladrón de Guevara. Por todo lo expuesto, parece improbable la presunta relación del Conde-Duque con la Real Congregación, al menos en los términos expuestos en el precitado catálogo.

Sin embargo, aún quedaría pendiente la localización documental del encargo o contrato de la obra al artista, y las noticias acerca de la suerte del cuadro desde su ejecución hasta que aparece documentado en la colección de doña Francisca Ladrón de Guevara para acabar de definir el círculo cortesano en el que se movió Alonso Cano.

Leticia M. DE Frutos SAStre Becaria de Formación de Personal Investigador (M.E.C.D.)

\title{
UNA ESCULTURA FUNERARIA INFANTIL DE MADERA EN EL INSTITUTO VALENCIA DE DON JUAN.
}

Entre las piezas que componen la colección de escultura del Instituto Valencia de don Juan encontramos la estatua orante de un niño, realizada en madera, tela encolada y yeso. Sus medidas son $77,5 \mathrm{~cm}$ de alto, $38 \mathrm{~cm}$ de ancho y $38,5 \mathrm{~cm}$ de fondo. Presenta elegancia señorial, carácter y vitalidad en su cabeza.

Aparece ante nuestros ojos con los mismos ademanes y la misma figura rígida y envarada que los adultos. La actitud recogida junto con su sencilla vestimenta acentúan el intimismo religioso del orante.

Se consideró que era interesante encontrar otros ejemplos de este tipo de escultura funeraria infantil en madera, material poco usado en este género debido a su propia naturaleza. La madera se asociaba a transitoriedad. Fue el material mayoritariamente usado para los grandes túmulos de la exequias regias por su carácter efímero. Sin embargo ofrecía algunas ventajas sobre los materiales pétreos o metálicos, como eran su bajo coste, su fácil obtención y transporte, su talla rápida y exenta de riesgos de quiebra de la pieza, la posibilidad de labrar la estatua en un solo bloque y la aplicación posterior de una policromía y dorado que proporcionara un mayor realismo y aspecto de riqueza a la figura sepulcral; caracteres que no convenían al monumento sepulcral pensado para la posteridad.

También interesaba la representación del niño en sí en el sepulcro familiar pues no son comunes los enterramientos infantiles. Uno de los pocos ejemplos de este tipo, con la particu-

${ }^{29}$ A. Rodríguez Rebollo en Alonso Cano. Espiritualidad y Modernidad artística, Cat. Exp. Hospital Real, Granada, (2002), p. 236. 
laridad de su temprana fecha situada en el primer tercio de siglo xVI, lo encontramos en la capilla Dorada de la catedral Nueva de Salamanca ${ }^{1}$.

El grupo formado por Diego Sánchez de Palenzuela, su mujer Isabel y su hijo Francisco, fundador de la capilla, tiene un tono entrañable. El tipo de representación del difunto es el orante $^{2}$. Así se nos presentan los padres, acompañados por su hijo, representado como niño, aprovechando el corto espacio disponible sobre la puerta de comunicación con la Catedral Vieja, provocando que aquellos sean un poco achaparrados.

Las figuras presentan indumentaria acorde con la época, el niño viste sayo corto y cerrado, con cuerpo ajustado y falda de vuelo hecha a nesgas, los padres llevan capa sobre sus vestidos, y la madre además de toca sostiene un rosario entre las manos, mientras que el padre porta una espada ${ }^{3}$.

Fuera de nuestras fronteras destaca la tumba de Jacques du Moulin, sieur de Briis, de Marguerite de Herbert, su mujer y de sus hijos Etienne, Pierre y Jacques en Sainte-Colombe de Servon en la segunda mitad del siglo XvI, lo cual ilustra sobre el gusto por la modalidad funeraria orante infantil por parte de la alta nobleza incluida la inglesa ${ }^{4}$.

Ello nos llevó a buscar los orígenes de la escultura orante funeraria para aplicarlos a la infantil.

Los orantes, en la modalidad funeraria que estudiamos, se independizan del contexto sobrenatural, el fiel adopta una actitud de continua oración, genuflexa y con las manos juntas, con una correcta orientación hacia el Altar-Retablo pero, posiblemente, hay que valorar que, también de esta manera, se puede aludir a la futura condición del difunto entre los benditos del Paraíso. Es una figura de eternidad, aunque todavía el personaje esté vivo ${ }^{5}$.

Tal vez debamos considerar el Altar-Retablo como la referencia que sustituye la imagen de devoción que en otros ejemplos estaba próxima al difunto. Todo contribuye a valorar la figura como representación viva del difunto.

Al parecer el origen del donante es nórdico, en oposición al tipo yacente, predominante en el arte sepulcral italiano. Los comienzos del orante en la plástica funeraria de nuestro país parecen confirmarlo. Si, según la afirmación hecha por Proske ${ }^{6}$ la representación arrodillada del difunto alcanzó durante el siglo xv mayor éxito en España que en otras partes de Euro$\mathrm{pa}^{7}$, esto fue posible por la afluencia de escultores flamencos que vinieron a trabajar a nuestro país. Se hace referencia, como posible antecedente del tipo en nuestra nación, a los sepulcros de la Escuela toledana ${ }^{8}$. Toledo inició la modalidad con las desaparecidas estatuas articuladas de D. Álvaro de Luna en su capilla funeraria de la catedral, fechadas en la quinta década del siglo xv. Más decisiva fue la aportación del escultor Egas Cueman, que en 1467 firma el contrato para realizar el sepulcro de Alonso Velasco e Isabel de Cuadros en la capi-

\footnotetext{
${ }^{1}$ M. ${ }^{2}$ José Redondo Cantera: El sepulcro en España en el siglo xvi: Tipología e iconografía. Madrid, Ministerio de Cultura, 1987, p. 129.

${ }^{2}$ La necesidad de colocar el monumento a cierta altura, por encima de la puerta, debió de influir en la elección de la representación orante, con objeto de facilitar su visión.

${ }^{3}$ A. Castro y J.C. Brasas: «La Capilla Dorada de la Catedral Nueva de Salamanca para el Catálogo de la exposición Las edades del hombre». El contrapunto y su morada». Salamanca, 1993, pp. 117-122.

${ }^{4}$ J. Adhémar: «Les tombeaux de la collection Gaigniéres». Gazete des Beaux-Arts, September, 1976, p. 91. Nigel Llewelyn, «English renaissance tombs: commemoration in Society», Arte Funerario. Coloquio Internacional de Historia del Arte II, México, 1987, 143-154: fig. 1, Tumba de Francis Smalman, con sus hijos, orantes (1635).

${ }^{5}$ Ph. Ariès: El hombre ante la muerte. Madrid, 1983, p. 214. También aborda el cuestión G. Bresc-Bautier. «Le teme du priant dans la sculpture francaise». Comunicación en el Seminario «¿Dejar a los muertos enterrar a sus muertos?» «El difunto entre el aquí y el más allá en España y Francia (ss. XI-Xv). 9-10 de diciembre de 1999. Casa de Velázquez y Universidad Autónoma de Madrid. (Actas en prensa).

${ }^{6}$ B. G. Proske: Castilian Sculture. Gothic to Renaissance. Nueva York, 1951, p. 74

${ }^{7}$ H. Wethey: Gil de Siloe and his school. Cambridge-Mass, 1936, p. 15.

${ }^{8}$ T. Pérez Higuera: «La escultura» en La España gótica. Castilla-La Mancha-1. Madrid, Ed. Encuentro, 1997, pp. 39-48.
}

AEA, LXXVI, 2003, 303, pp. 301 a 329 

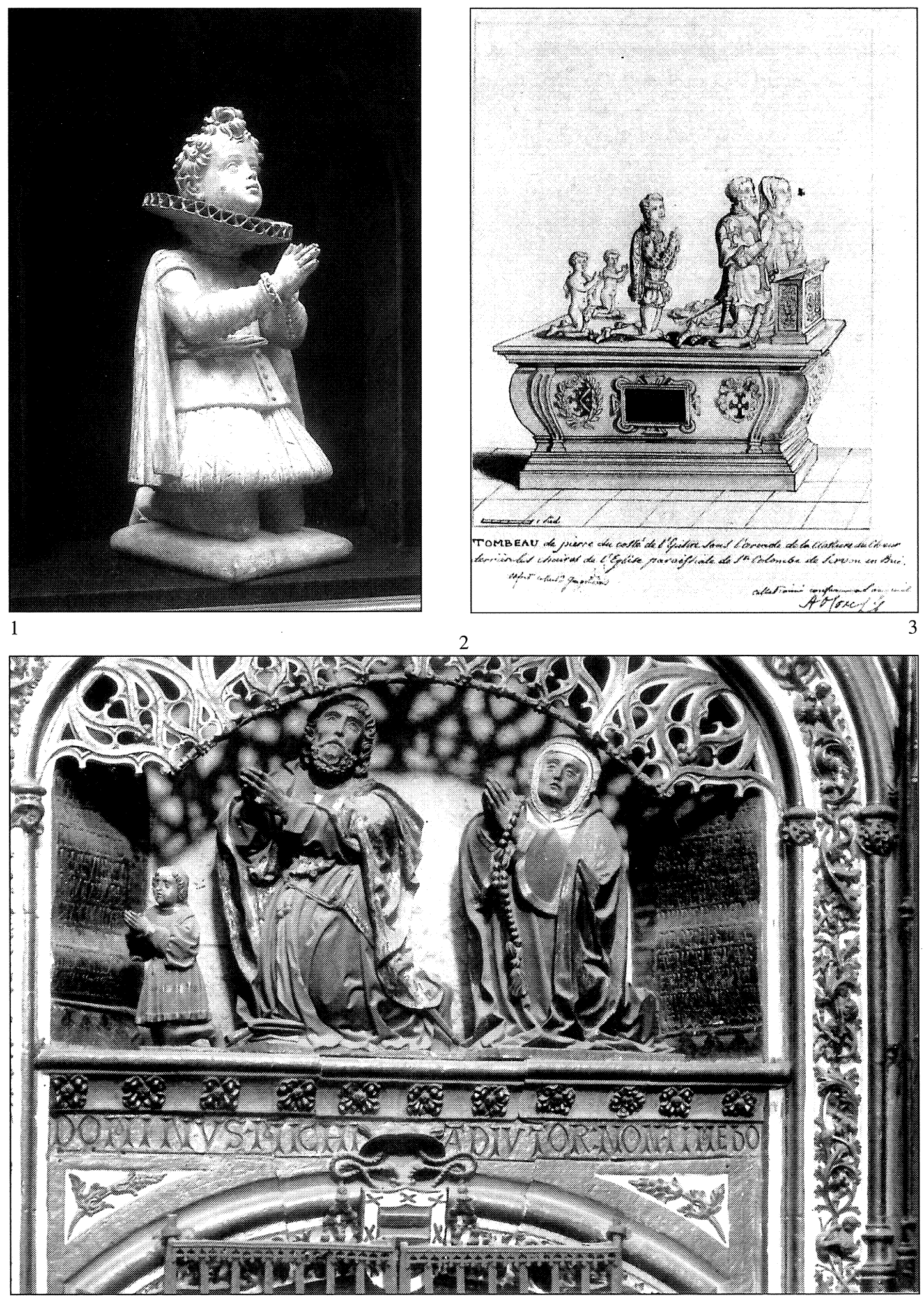

Fig. 1. Niño orante. Madrid, Instituto Valencia de Don Juan.

Fig. 2. Sepulcro de Diego Sánchez de Palenzuela y familia. Salamanca, Catedral, Capilla Dorada.

Fig. 3. Sepulcro de Jacques de Moulin y familia. Sainte Colombe de Servon.

AEA, LXXVI, 2003, 303, pp. 301 a 329 
lla de Santa Ana del Monasterio de Guadalupe ${ }^{9}$.Los protagonistas arrodillados ante reclinatorios, en actitud orante, están acompañados por dos pajes. A fines del siglo, el tipo se hace más frecuente y tiene siempre carácter monumental. En esta línea destacan los sepulcros del infante don Alfonso, en la cartuja de Miraflores en Burgos; el de Juan Arias del Villar, en la catedral de Oviedo; el de Pedro de Acuña, en la iglesia de Santa María de Dueñas (Palencia). Continuador de éstos el de Juan de Padilla, datable hacia 1500 y relacionado directamente con la actividad de Gil de Siloe. Procedente del Monasterio de Fredesval se conserva actualmente en el Museo de Burgos.

La representación genuflexa del difunto, que conoció un gran éxito en Francia durante los siglos XVI y XVII, se ubicó indiferentemente en sepulcros exentos o en monumentos murales. En España, sin embargo, el orante se vinculó a un monumento funerario de tipo mural. A pesar de ello, hay unos ejemplos exentos con carácter de excepción. El más importante de ellos, la estatua sepulcral de San Segundo, obra de un artista de origen borgoñón, Juan de Juni. Dentro de la órbita francesa había que situar también el de Martín Zurbano, en la iglesia de San Sebastián de Azpeitia (Guipúzcoa).

En el último tercio de la centuria se asiste a un florecimiento de la estatua sepulcral orante. Factores de diversa índole contribuyen a ello. El espíritu de la Contrarreforma prefiere la actitud confesional y activa de la figura en oración, frente a la postura pasiva del yacente. La demanda de un naturalismo cada vez mayor, por otra parte, favorece la inclinación por este tipo, ya que en él son más fácilmente visibles los rasgos personales de difunto. La intervención personal de algunos artistas y su predilección por el tipo, entre los que destacan Esteban Jordán y sobre todo Pompeyo Leoni, será decisiva también para su implantación definitiva ${ }^{10}$.

La representación orante del difunto ofrece varias ventajas sobre la yacente. Además de presentar al fiel cristiano en una actitud más activa, su postura erguida permite una mejor visión de la estatua, aunque se la coloque a una altura mayor que el yacente, lo que garantiza una mejor protección de las figuras. Además, es posible introducir en un mismo nicho varias figuras permaneciendo todas a la vista del espectador. Con ello, el nuevo tipo se adapta también a las necesidades de la nueva sensibilidad familiar y religiosa que surge a partir del siglo $\mathrm{XVI}^{11}$. El exponente más claro de este agrupamiento familiar en el sepulcro lo constituyen los mausoleos real e imperial de El Escorial. En el grupo de Carlos V se incluyen las figuras del Emperador, su esposa Isabel de Portugal, sus hermanas Leonor y María, y su hija María. Felipe II es acompañado en el suyo por tres de sus cuatro esposas y su primogénito.

Con ello se advirtió que aunque es muy común la escultura funeraria orante en el siglo XVI en España, no son conocidos enterramientos de grupos familiares con niños. Salvo el ejemplo recogido, entre otros libros, en la obra de la doctora Redondo.

Sin embargo de estas fechas encontramos las tumbas de los XII Condes de Niebla, fechadas en 1607 y situadas en los laterales del presbiterio del convento de Santo Domingo en Sanlúcar de Barrameda (Cádiz). Un ejemplo de difusión de El Escorial y también uno de los más tempranos fuera del área cortesana.

Las conexiones con el modelo escurialense se establecen a través del VI Duque de Medina Sidonia que se sabe por documentos que Felipe II lo recibió en 1593 en el Escorial. Para su realización acudió a Francisco de la Gándara, todavía desconocido escultor, por entonces residente en Sanlúcar. Tallados en madera, tela encolada y yeso, la historiografía local ha venido señalando que no podían ser los originales, ya que entendía que la grandeza de la Casa de Medina Sidonia no era compatible con unas esculturas de materiales tan poco nobles. Perdida

\footnotetext{
${ }^{9}$ Fr. G. Rubio e I. Acemel: «El maestro Egas en Guadalupe». B.S.E.E., XX, 1912, pp. 190-229.

${ }^{10} \mathrm{M}^{\mathrm{a}}$ José Redondo Cantera: El sepulcro..., p. 127.

${ }^{\prime \prime}$ Ph. Ariès: El hombre..., p. 252.
}

AEA, LXXVI, 2003, 303, pp. 301 a 329 
en gran parte la policromía, lo que hoy se aprecia es la capa de preparación, sobre la que se ha intervenido repetidamente; dato que ha contribuido a que se consideraran réplicas de los primitivos, que se creían de bronce, mármol o alabastro.

«Sus estructuras arquitectónicas evidencian el conocimiento de los prototipos por parte del comitente. Dispuestas a igual altura, presentando una misma ordenación, aunque más simplificada en el caso de la tumbas condales, de un solo vano, pero igualmente adintelado. También difieren en el remate, ausente en el caso sanluqueño, en el que los escudos nobiliarios aparecen a ambos lados de las inscripciones situadas en la parte inferior. Las columnas tampoco son iguales, ya que los capiteles son corintios, no dóricos, y el fuste está estriado de forma helicoidal.

Pese a todo remiten al modelo escurialense, con el que guardan mayor conexión las figuras de los orantes. En el lado del Evangelio aparece en primer lugar la del XII Conde de Niebla, arrodillado sobre un cojín y con un breviario en las manos, situándose delante de él un reclinatorio cubierto de ricas telas. Ante él se halla su hijo don Juan Alonso también arrodillado sobre un cojín y en actitud orante. Más adelante la de su hijo don Esteban. Delante de todos se sitúa la imagen de uno de sus nietos. En el otro lado aparecen las figuras de la Condesa de Niebla, arrodillada orando ante un reclinatorio sobre el que aparece abierto un gran libro, la de su hija doña Ana de la Cruz y la de sus nietas» ${ }^{12}$

Este hallazgo nos animó a buscar algún ejemplo que pudiera haberse dado en Madrid. En la monografía de la Doctora Tovar sobre Gómez de Mora nos llamó la atención el proyecto de la Capilla Mayor de la Iglesia del monasterio de San Martín. Se revisaron los documentos acerca de la obra y se localizaron las noticias dadas, que conseguimos ampliar en la consulta de los documentos del A.P.M., que completaban los conocidos por Virginia Tovar y que expondremos a continuación.

La parroquia de San Martín considerada como una de las más antiguas de la ciudad, en un barrio cercano al Alcázar, por ello centro de devoción de gran parte del personal vinculado a Palacio, fue objeto de remodelaciones en el siglo XVII ${ }^{13}$.

La obra más importante de toda la reforma emprendida fue la Capilla Mayor. Se había de hacer con arreglo a la traza de Juan Gómez de Mora y ejecución de Gaspar Ordóñez según contrato firmado el 1 de enero de 1611 por encargo de doña Catalina de Medina, viuda de don Alonso Muriel ${ }^{14}$.

El Monasterio de S. Martín debió contar con la protección de la citada familia en tiempos anteriores, ya que la lectura del testamento de Alonso Muriel, de 22 de marzo de 1609, muestra la encomienda de que su cuerpo y armas sean sepultadas en la Iglesia de S. Martín en la sepultura donde están enterrados sus padres, donde se hará una bóveda y en ella se depositará su cuerpo hasta que su mujer ordene su sepultura de la manera que los dos tienen tratado y donde quiera que ordenare el entierro, que ha de ser perpetuo para su cuerpo, se lleven los huesos de sus padres. Ordena se instituya en la parte que hubiere de ser su entierro y de sus padres, una capellanía de ochocientos ducados anuales ${ }^{15}$.

Siguiendo estas indicaciones su viuda, Catalina de Medina y Zarauz, inicia las gestiones para establecer patronazgo sobre la Capilla de la iglesia del convento de S. Martín. Así el 5 de octubre de 1609 obtiene del cardenal de Toledo, D. Bernardo de Sandoval y Rojas aprobación

\footnotetext{
12 J. Miguel Serrera Contreras: «El eco de El Escorial. Las tumbas de los XII Condes de Niebla» en Felipe II y el arte de su tiempo. Fundación Argentaria, Madrid, 1998, pp. 167-183. J. M. Palomero Páramo: El retablo sevillano del Renacimiento: Análisis y evolución (1560-1629). Sevilla, 1983.

${ }^{13}$ E. Tormo: Las iglesias del antiguo Madrid. Madrid, 1929. P. Madoz: Diccionario Geográfico-Estadístico-Histórico. Madrid, 1948, p. 196.

${ }^{14}$ V. Martín Tovar: Juan Gómez de Mora (1586-1648) Arquitecto y trazador del rey y maestro mayor de obras de la villa de Madrid, Museo Municipal de Madrid, Mayo, 1986, pp. 83-86.

${ }^{15}$ Archivo de Protocolos de Madrid. P. ${ }^{\circ}$ N. ${ }^{\circ}$ 952, F. ${ }^{\circ} 1169$
} 
para el concierto entre los monjes y ella. Unas fechas más tarde, 26 agosto de 1610, es el general de la congregación de San Benito, fray Plácido de Todos los Santos, quien da el visto bueno. Y tras la aprobación de los monjes de San Martín se firma la «Scriptura de Asiento Concierto Venta y Obligación entre el abad y los monjes de San Martín con $D^{a}$. Catalina», a 6 de septiembre de 1610 ante el escribano Francisco Testa. Con ella se obtiene patronazgo perpetuo sobre la Capilla Mayor debiendo dar treinta mil maravedís de renta cada año. La cual libre y desembarazada de todos los cuerpos enterrados, se sitúa y delimita: 26 pies de ancho y 22 pies de fondo, hueco que quedará cerrado por una reja. Podrá hacerse bóveda debajo del altar mayor para entierro del señor Alonso, de doña Catalina y sus sucesores, así como dos nichos en las paredes colaterales para poner sus tumbas. $\mathrm{Y}$ ha de poder hacer gradas y retablo principal; adornando la capilla como conviene, incluyendo sus escudos de armas.

También señala la apertura en el lado de la epístola de una ventana con balcón de una tercia de vuelo para que desde la tribuna, que se ha de hacer en la capilleja adjunta, se pueda oír misa, pudiendo abrir y poner en ella o debajo una puerta para salir a la capilla mayor a recibir el santo sacramento ${ }^{16}$.

En cumplimiento de lo pactado en dicha escritura D. ${ }^{a}$ Catalina firmará contrato de reja (30 de noviembre de 1610), obra de albañilería (1 de enero de 1611) y concierto de retablo (6 de enero de 1611) para la Capilla Mayor de San Martín ${ }^{17}$.

Y es en la Memoria y condiciones de la obra de yesería, albañilería y mampostería, que se había de hacer con arreglo a la traza de Gómez de Mora y ejecución de Gaspar Ordóñez, donde nos vamos a detener. En uno de sus párrafos se señala: Es condición q' en corespondencia de este encasamento q'se ha de hacer para la tribuna i oratorio sea de hacer enfrente otro encasamento q' corresponda desde el segundo suelo i tenga de hondo dos pies poco mas o menos donde esten los bultos i retratos con el hornato i vuelta que enseña el perfil i para hacer el dicho encasamento sea de hacer un arco de ladrillo rosado en la parte de ariba para baciar el encasamento después de echo el arco i a de quedar jarrado $i$ blanqueado i faxeado como lo enseña el perfil.»

Y serían esos retratos que se habían de situar en el encasamento del lado del evangelio de la citada capilla mayor los correspondientes al señor secretario Alonso Muriel e hijos.

El dibujo de Gómez de Mora para la capilla-enterramiento de la familia, nos muestra una experiencia de suma sencillez, como corresponde a un enterramiento en un espacio no demasiado amplio. Sin embargo, en ella se contemplan una serie de elementos de escultura, pintura y arquitectura bien coordinados.

Según el dibujo existente en el A.P.M.: Prot. 953, fol. 136 apunte sobre un proyecto más elaborado, pero en el que se puede apreciar la dependencia que presentan todavía las capillas funerarias, de la obra suntuosa de El Escorial. La capilla funeraria se alza sobre una gradería de siete peldaños a partir del nivel de la iglesia de la que se separa por un gran arco de medio punto. La estructura arquitectónica está caracterizada por elementos armónicos que cumplen su función para conformar una pantalla absidal con su carácter funerario. Gómez de Mora acostumbra a integrar «la figura» dentro del esquema arquitectónico contribuyendo a que la proporción y la composición ofrezca mayor coherencia. El arquitecto ha querido relacionar el propio luneto de la bóveda con el simplificado medio punto con remate termal del retablo funerario ${ }^{18}$.

\footnotetext{
${ }^{16}$ Archivo de Protocolos de Madrid. P. ${ }^{\circ} .^{\circ} 2640$, F. $^{\circ} 153,152,154,140$.

${ }^{17}$ Archivo de Protocolos de Madrid. P. ${ }^{\circ}$ N. ${ }^{\circ} 953$, F. $^{\circ}$ 142, 134,1. Más ampliamente V. Martín Tovar: Juan Gómez de Mora (1586-1648) Arquitecto y trazador del rey y maestro mayor de obras de la villa de Madrid, Museo Municipal de Madrid, Mayo, 1986, pp. 83-86.

${ }_{18}$ V. Martín Tovar: Arquitectura madrileña del siglo xvII (Datos para su estudio). Madrid, I.E.M., 1983, p. 767. Catálogo de Gómez de Mora, Madrid, 1983, p. 231.
}

AEA, LXXVI, 2003, 303, pp. 301 a 329 

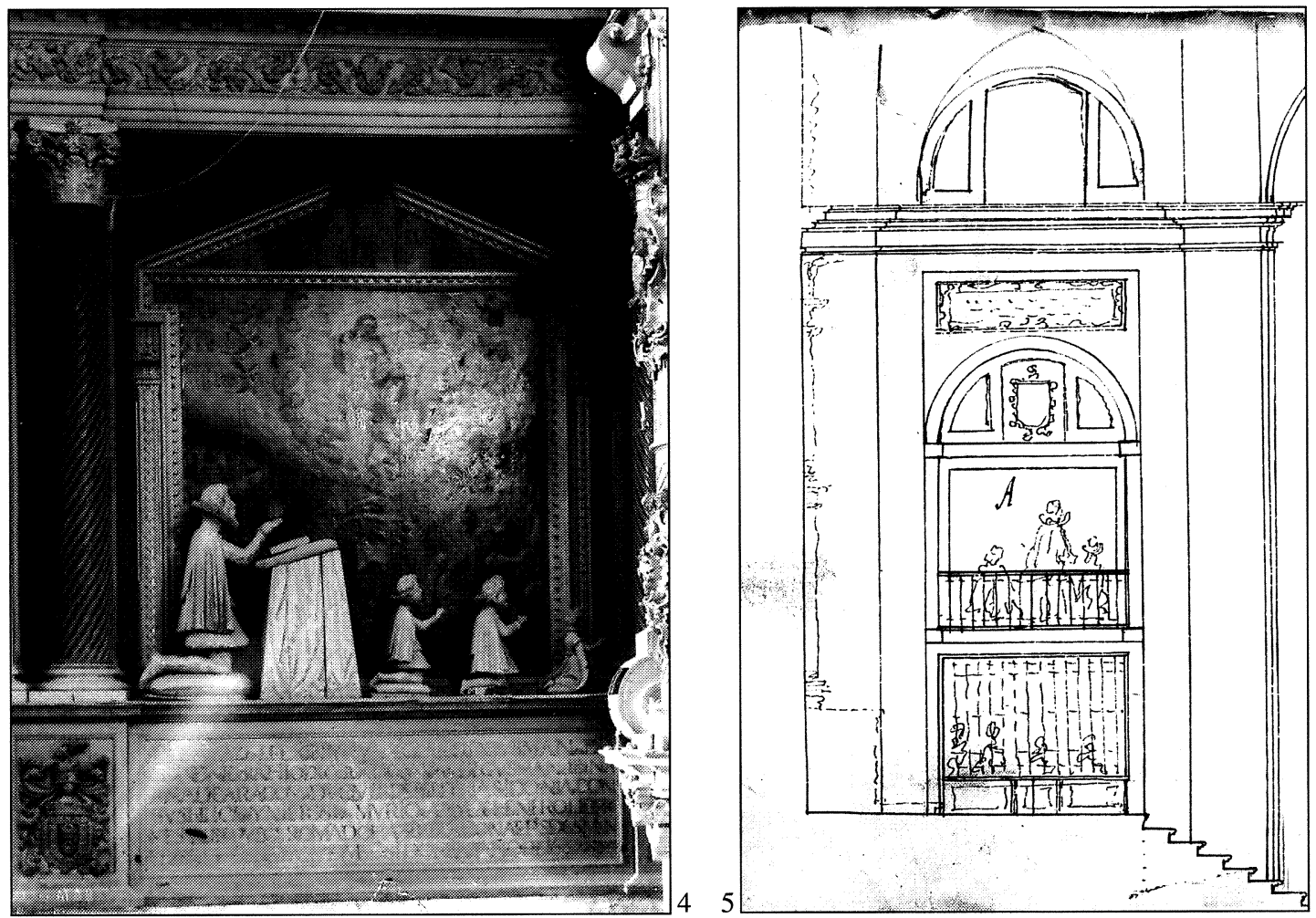

Fig. 4. Sepulcro de los XII Condes de Niebla. Sanlúcar de Barrameda (Cádiz), Convento de Santo Domingo.

Fig. 5. Gómez de Mora: Traza del sepulcro de D. ${ }^{a}$ Catalina Medina y Zarauz. Madrid, Convento de San Martín.

Aunque no apareció en los documentos consultados es posible que los bultos los subcontratara Juan Muñoz, el responsable del retablo al que acompañaban, como es común en la época. Juan Muñoz generalmente aparece en la escultura madrileña de la época como empresario y retablista que encomienda la labor de imaginería y escultura a otros artistas como es el caso de Juan González, que llevó a cabo las siete figuras del retablo de la Encarnación de Madrid, o Antonio Herrera que realiza diez figuras para el retablo de Santo Domingo el Real, ambos contratados por Muñoz ${ }^{19}$.

Aunque insistimos en la búsqueda del contrato de los bultos no lo hemos localizado pero es muy posible que se encuentre entre las farragosas escrituras de la amplia documentación de estos años que conserva el Archivo de Protocolos de Madrid.

Resumiendo la pieza estudiada es ejemplo interesante de escultura funeraria infantil, cuya indumentaria es considerada por Carmen Bernis como ejemplo de principios del siglo XVII. Lleva capa con «capilla» cerrada sobre la ropilla, calzas de «muslos tendidos» en su versión corta y el cuello de lechuguilla muestra la exageración propia de estos años. El manto en pliegues suaves cae a los lados sin advertirse en ellos sutilezas, pero sus manos son delicadas y expresivas ${ }^{20}$. Y sería interesante seguir nuestra búsqueda para añadir a los ejemplos citados otros modelos existentes.

19 A. Bustamante García: «Juan Muñoz, escultor». B.S.E.A.A., t. XXXIX, Valladolid, 1973, pp. 269-284. M. Estella Marcos: «Aspectos inéditos de la escultura madrileña de hacia 1600: Juan Muñoz, Antonio de Herrera y una escultura italiana en el Retiro». III Jornadas de Arte. Cinco siglos de arte en Madrid (XV-XIX). Departamento de H. ${ }^{\mathrm{a}}$ del Arte. Centro de Estudios Históricos, C.S.I.C. Madrid, 1991.

${ }^{20}$ C. Bernis: «La moda en la España de Felipe II a través del retrato de corte», en Alonso Sánchez Coello y el retrato en la corte de Felipe II. Madrid, 1996, pp. 65-111. 
Queda también la duda de si la figura por estar en Madrid pudiera corresponder al enterramiento proyectado por Gómez de Mora, pero el estilo no es definido para asignarlo a un artista concreto y por otra parte no se conoce, como se ha dicho, el escultor que llegó a realizar el sepulcro proyectado por dicho maestro.

Como datos a favor de la propuesta está la fecha del proyecto de Gómez de Mora, aunque pensamos que el arquitecto no hubiera propuesto una figura en madera, material poco usado, salvo en el sepulcro de los Barrionuevo en Fuentes (Guadalajara), donde la escultura principal de bronce de D. García obviaba el hacer unos enterramientos de categoría existiendo éste de San Ginés de Madrid ${ }^{21}$.

Además, y por último, quisiéramos destacar que las piezas de un Museo como el Valencia de D. Juan donde, como en otros muchos museos de sus características, no suele existir la documentación pertinente que pudiera permitir conocer su procedencia facilitando su clasificación.

Carmen Fernández AhiJAdo I.E.S. «Leandro Fernández de Moratín» Guadalajara

\section{PEDRO DE CASTAÑEDA: SU PINTURA PARA EL REFECTORIO DEL COLEGIO MAYOR DE S. ILDEFONSO (1553)}

El pintor Pedro de Castañeda es un artista poco conocido, activo en la zona de Alcalá de Henares en las décadas centrales del siglo xvi. Se sabe que junto a su hijo Juan fue colaborador del entallador y traductor de Vitruvio Miguel de Urrea. Pedro de Castañeda pintó un cirial que había tallado Urrea para la iglesia parroquial de Camarma de Esteruelas, trabajo por el que ambos cobraron cierta cantidad en 1540, y en 1550 colaboró con ese entallador y con Claudio de Arciniega, ayudado por Juan, en la obra de los retablos colaterales de la iglesia de Daganzo de Arriba (perdidos), realizando su pintura. Parece que se trata del mismo artista el Pedro Castañeda que se documenta trabajando en la zona de Segovia, concretamente en dos retablos para la iglesia de Cascajares del Fresno. Falleció en $1557^{1}$.

Como es lógico, por tratarse de un pintor activo y con taller en Alcalá de Henares, Castañeda fue uno de los artistas del siglo xvi con los que podía contar la Universidad fundada por el Cardenal Cisneros en la villa complutense para las obras de pintura que la institución académica encargase, dado el caso. Tenemos una somera noticia que indica que un pintor llamado Castañeda, y que podemos identificar con el que nos ocupa, fue contratado para un trabajo auxiliar en la fábrica de la monumental fachada del Colegio Mayor de S. Ildefonso, que los colegiales decidieron levantar en 1537 y en obra hasta su inauguración en 1553, cuya construcción fue dirigida por Rodrigo Gil de Hontañón. Concretamente se pagaron el 12 de noviembre de 1544 «tres reales a Castañeda porque pintó dos figuras y dio de pintura a lo que el señor Rodrigo Gil había traça-

\footnotetext{
${ }^{21}$ M. Estella Marcos: «Problemas dela escultura cortesana de hacia 1600: Porres, el nacherino y otros». Real Palacio de El Escorial. Estudios inéditos del IV Centenario de la terminación de las obras. Departamento de Arte de I. Diego Velázquez, C.S.I.C. Madrid, 1987, pp. 221-240. M. ${ }^{a}$ C. Gracia Abad: El Señorío de Fuentes de la Alcarria, Guadalajara, 1994, pp. 192-196.

' J. M. Cruz Valdovinos, «Miguel de Urrea, entallador de Alcalá y traductor de Vitruvio», Anales del Instituto de Estudios Madrileños, XVII, 1980, p. 69; M. A. Castillo Oreja, «La eclosión del Renacimiento: Madrid entre la tradición y la modernidad», en Madrid en el Renacimiento, Alcalá de Henares-Madrid, 1986, pp. 156-158; F. Collar de Cáceres, La pintura en la antigua Diócesis de Segovia (1500-1630), Segovia, 1989, p. 64; J. M. Cruz Valdovinos, «Retablos de los siglos xv y xvi en la Comunidad de Madrid», Retablos de la Comunidad de Madrid, Madrid, 1995, p. 44.
}

AEA, LXXVI, 2003, 303, pp. 301 a 329 